\title{
La contribution culturelle des néo-ruraux au Québec : l'exemple de Brome-Missisquoi
}

\author{
Myriam Simard \\ Institut national de la recherche scientifique (INRS)
}

\section{Introduction}

L'occupation des espaces ruraux est en transformation au Québec avec, notamment, l'arrivée dans certains territoires de populations rurales variées (retraités, jeunes familles en quête de qualité de vie, immigrants, artistes et autres travailleurs autonomes... $)^{1}$. Il en résulte une complexification des populations rurales ainsi qu'une diversification des usages de la campagne (productifs, résidentiels, récréatifs et de préservation). De nouveaux rapports sociaux entre les divers résidents ruraux sont donc susceptibles d'émerger à la faveur de cette mutation sociodémographique des campagnes. Qui n'a pas déjà entendu parler d'expériences heureuses ou malheureuses de "néo-ruraux » ayant quitté la ville pour venir s'installer de façon permanente à la campagne ? Qui n'a pas lu dans les médias les conflits de ces nouveaux ruraux avec les agriculteurs ou la population locale?

Le but de cet article est double. D'abord, montrer par l'exemple de la MRC de Brome-Missiquoi que la contribution de ces nouvelles populations rurales va bien au-delà des seules retombées économiques et démographiques usuelles et qu'elle est notable au niveau culturel. D'autre part, dépasser la vision souvent négative et conflictuelle sur ces nouveaux résidents pour montrer leur apport positif dans la revitalisation rurale. J'ai déjà exposé ailleurs, dans un article ${ }^{2}$, la nécessité de porter un regard nuancé sur les multiples interactions dans la société rurale contemporaine. Ainsi, y décèle-t-on non seulement des tensions et des conflits entre les diverses populations rurales, mais aussi des alliances et des solidarités autour d'enjeux communs. Je me concentrerai donc sur leur contribu- tion culturelle puisqu'elle permet de bien illustrer mes propos.

Les résultats présentés ici sont tirés d'une étude sur les nouvelles populations rurales ayant migré de la ville à la campagne que j'ai réalisée récemment avec mon équipe à l'Institut national de la recherche scientifique en 2006 et 2007. Ils concernent à la fois un sondage auprès des néo-ruraux ainsi que des entrevues en profondeur auprès de quatre types d'acteurs (néo-ruraux, ruraux de longue date, élus municipaux et autres acteurs clés locaux). Au départ, deux MRC contrastées ont été sélectionnées: Brome-Missiquoi où les nouveaux ruraux sont davantage des retraités, et Arthabaska où se retrouvent surtout des jeunes familles ${ }^{3}$. Je ne me pencherai ici que sur la MRC de Brome-Missisquoi puisque c'est là où la contribution culturelle des nouvelles populations rurales est le plus visible. Des extraits d'entrevues de néo-ruraux viendront tout au long de l'article enrichir les premiers résultats du sondage quant à cet apport culturel dans ce territoire. Leurs témoignages permettront d'illustrer les grandes tendances de l'analyse sur cet aspect.

Il ne faut pas confondre les nouvelles populations rurales, dénommées aussi « néo-ruraux », avec les populations périurbaines vivant dans des banlieues à proximité de centres urbains importants. Il s'agit plutôt d'ex-urbains ayant déménagé à la campagne de façon durable et qui travaillent généralement près de leur nouvelle résidence. Leur problématique globale d'insertion est alors fort différente de celle des navetteurs. De même, les néo-ruraux n'incluent pas les populations plus saisonnières tels les villégiateurs, touristes et visiteurs de fins de semaine. Les néoruraux de l'étude sont donc des individus établis en 
permanence dans une municipalité rurale depuis moins de vingt ans, alors que les ruraux de longue date comprennent en grande majorité des personnes nées dans la MRC et plus secondairement qui y sont établies depuis plus de vingt ans. Quant aux acteurs clés, ce sont, outre les élus municipaux, les directeurs d'organismes locaux et régionaux et les responsables d'associations villageoises.

\section{Bref aperçu de la MRC de Brome- Missisquoi et de la population étudiée}

La consultation aussi bien de personnes-ressources du milieu que de spécialistes de divers organismes (Statistique Canada, Secrétariat rural, ministère des Affaires municipales et des Régions...) ainsi que l'analyse de diverses sources de données secondaires ont bien mis en évidence la pertinence du choix de la MRC de Brome-Missiquoi pour observer la recomposition sociodémographique de l'espace rural. Des transformations s'observent tant par l'arrivée de retraités, souvent des ex-villégiateurs, que par l'installation de nouvelles familles avec leurs enfants. En outre, une longue histoire d'inclusion de nouveaux arrivants (anglais, français, américains, immigrants...) lui donne un certain avantage ${ }^{4}$.

Cette MRC localisée au sud du Québec, soit aux limites des régions administratives de l'Estrie, de la Montérégie et de l'État du Vermont (États-Unis), se situe à environ une heure et demie de route de Montréal et de Sherbrooke. Selon le dernier recensement canadien, une population totale de 46720 personnes y habitait en 2006 avec une densité moyenne de 30,4 personnes par kilomètre carré. Elle compte 20 municipalités, dont 19 sont des municipalités rurales ayant une population oscillant entre 278 et 7809 habitants. La ville la plus populeuse est Cowansville avec 12182 habitants. Celle-ci figure comme un important pôle de services pour les autres municipalités (carte 1). La MRC accueille une population mixte au plan linguistique : $73,6 \%$ sont de langue maternelle française, 22,6\% de langue maternelle anglaise et 2,1\% de langues non officielles.

\section{Carte 1 - MRC de Brome-Missisquoi et ses municipalités}

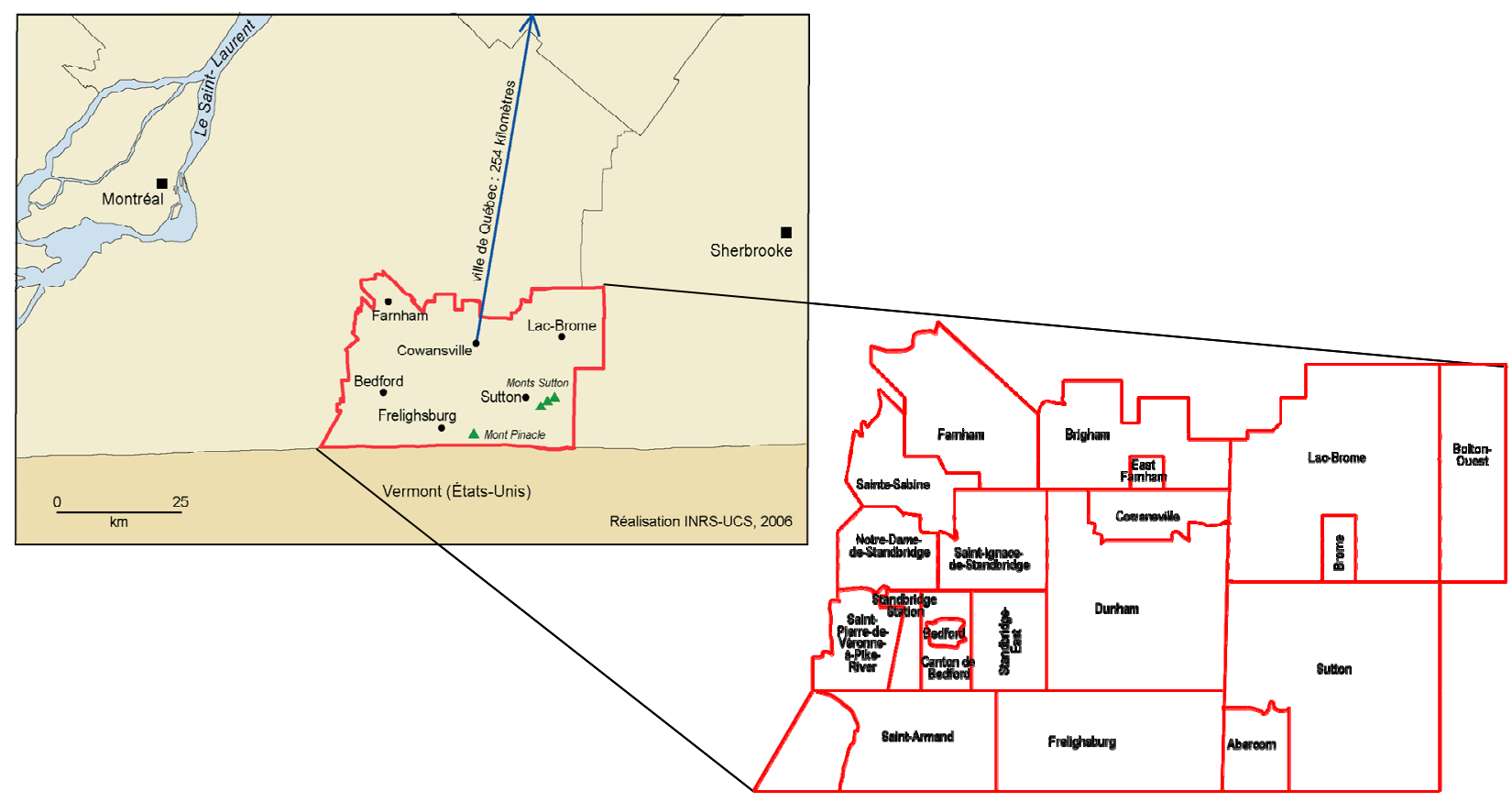

Cette MRC comprend deux territoires contrastés au point de vue géographique et socio-économique. D'abord, la portion ouest caractérisée par les plaines montérégiennes où se retrouvent de grandes cultures (maïs, élevage de porc, fermes laitières, volaille, etc.), plusieurs petits villages à vocation agricole et un secteur industriel et manufacturier important. Par contre, le secteur est, avec le massif des monts Sutton et le mont Pinacle, est plus montagneux. Les principaux moteurs économiques en sont le tourisme et la villé- 
giature. La population y est plus âgée que dans l'ouest, avec les 60 ans et plus comptant pour près du tiers $(30 \%)$. Elle est également plus scolarisée et mieux nantie.

Historiquement, les nouveaux résidents se sont établis davantage dans le secteur est. Ceci se reflète dans le groupe des nouveaux ruraux interrogé lors du sondage : 77,0 \% résident dans le secteur est de BromeMissisquoi, comparativement à 23,0\% vivant dans le secteur ouest. Ainsi, un total de 100 néo-ruraux installés de façon permanente depuis un minimum d'un an et un maximum de 20 ans ont ainsi pu être interrogés lors de ce sondage téléphonique. Ce dernier fut complété par 46 entrevues en profondeur dans la MRC (23 nouveaux ruraux, 12 ruraux de longue date, 5 élus municipaux et 6 acteurs clés locaux).

Le sondage a révélé une implication active des néoruraux dans la communauté puisque les deux tiers s'engagent dans diverses activités de bénévolat. Fait important, ce sont davantage les associations culturelles et artistiques qui attirent ces néo-ruraux bénévoles. En effet, la moitié d'entre eux s'y engagent (51,5\%), alors que $37,9 \%$ se portent volontaires au sein d'associations sociales et communautaires, et $19,7 \%$ dans des associations environnementales. À noter que leur engagement est souvent hétérogène et multiple, la plupart ayant identifié une participation bénévole dans différents types d'organismes. Je ne me concentrerai ici que sur leur engagement culturel et artistique.

\section{Contribution culturelle}

\section{Les néo-ruraux bénévoles}

Qui sont ces néo-ruraux qui s'investissent bénévolement dans Brome-Missiquoi ? Comme on pouvait s'y attendre, ce sont davantage des personnes retraitées ou semi retraitées $(64,2 \%)$ puisqu'elles bénéficient de plus de temps libre que les autres groupes d'âge. Ces bénévoles sont en majorité âgés de 60 ans et plus $(56,1 \%)$, et on y compte plus de femmes que d'hommes, en concordance avec une étude canadienne sur le bénévolat artistique et culturel ${ }^{5}$. Comme les études et les emplois d'un bon nombre des néo-ruraux (retraités ou encore actifs) se sont concentrés notamment dans le domaine des arts et de la culture, il n'est pas surprenant que l'on voie émerger un bénévolat dans ce domaine, surtout dans la partie est du territoire.
Sutton figure en effet comme la cinquième municipalité du Canada accueillant la plus forte proportion d'artistes, soit $6,0 \%^{6}$, ce qui a sûrement un effet incitatif et d'entraînement à l'égard de l'engagement culturel.

Outre le bénévolat, il convient de noter que les troisquarts des néo-ruraux participent activement comme spectateurs ou simples membres aux diverses manifestations artistiques et culturelles de la région, dans un souci d'encourager et de consolider les activités culturelles existantes. Ainsi, ils fréquentent les concerts, les divers spectacles et événements artistiques, les bibliothèques, etc. Cela rend encore plus tangible leur contribution multiforme dans la vitalité culturelle locale.

\section{Les organisations culturelles où les néo-ruraux s'engagent et les principales activités}

Diverses catégories d'organismes culturels sont investies par les bénévoles néo-ruraux : organismes d'histoire et de patrimoine, salles de spectacle ou de théâtre, comités variés (politique culturel, réseau d'artistes, événements spécifiques locaux tels le Tour des Arts, la Tournée de 20, le Festiv'Arts, le Festival des films du Monde de St-Armand...), galeries d'art, bibliothèques et cinéma, etc. Les activités y sont diversifiées et concernent toute la panoplie de tâches nécessaires à une vie culturelle dynamique dans le milieu. Ils peuvent participer, par conséquent, à des tâches aussi variées que l'organisation et la publicité année après année d'événements locaux, le recrutement de nouveaux membres, la sollicitation d'artistes locaux comme parrains d'événements spéciaux, le repérage et la mise en valeur de l'histoire locale : " Il va y avoir des dépliants, calendriers, fêtes champêtres, dans le sens que la fête au village, en 2007, c'est le bicentenaire de l'église anglicane. [Elle a de superbes vitraux, c'est vraiment un lieu à protéger]. Donc, c'est pour ça que j'y travaille [bénévolement] de deux à trois jours semaine. L'an dernier, on a fait un album souvenir sur 1'histoire de Frelighsburg et sa population. » (Néo-rurale 12)

D'autres s'engagent davantage dans les levées de fonds, la formation et la consolidation de réseaux d'artistes, la fondation d'un carrefour culturel, la création de spectacles de musique ou d'événements spéciaux lors des fêtes importantes [Noël...], la mise en place de chorales, de troupes de théâtre et de ligues 
d'improvisation, l'élaboration et la mise en œuvre de politiques culturelles : «Je fais partie du comité de travail sur la politique culturelle. Or, c'est un comité qui est entièrement bénévole. On aide la ville à construire son dossier pour créer une politique culturelle. [...] [Puis, je suis] bénévole au Cæur du village [salle de spectacle]. Moi, ça me dérangeait pas du tout d'être à la porte, puis de ramasser des billets. Je n'ai jamais fait ça de ma vie, mais aucune importance, le plaisir c'est d'être là puis d'être parmi un groupe de gens. [...] Cela m'a donné un sentiment d'appartenance. $[. .$.$] Je ne me considère pas comme une béné-$ vole, je me considère comme une participante. Je fais partie de l'équipe qui fait rouler cette place-là.» (Néo-rurale 1)

Ces témoignages permettent d'entrevoir que ces bénévoles sont polyvalents et n'hésitent pas à apporter leurs énergies, expertises ou mêmes d'anciennes compétences dans divers lieux afin de maintenir et de bonifier l'offre culturelle dans la MRC. Certains vont même occuper un poste de direction dans des organisations ou des comités liés à la culture.

\section{L'engagement bénévole des néo-ruraux entraîne souvent le développement d'activités originales venant répondre à certains besoins.}

\section{Retombées globales}

L'analyse de l'impact culturel dû à la migration et à l'installation permanente de nouvelles populations rurales est présentement en cours. Une analyse préliminaire permet déjà de déceler quatre retombées principales.

\section{Création de nouvelles activités}

Les néo-ruraux, en prenant conscience du potentiel culturel de la région, ont de nouvelles idées et élaborent des projets originaux pour renforcer et enrichir le dynamisme culturel local, tel que le relate cet élu municipal : " Ce sont les néo-ruraux plutôt qui viennent [...] puis qui nous présentent des projets, comme je vous dis, le Festival du film du Monde de SaintArmand, des choses comme ça, et qui impliquent les deux [populations - nouvelle et de longue date]. [...] Ils sont plus friands d'histoire, d'architecture, de patrimoine. [...] Ils ont souligné certains aspects du coin qu'on prenait pour acquis [...] et montré aux gens qu'ils avaient certaines belles affaires [maisons et styles]. [...] Ils ont fait un petit journal local, puis ils y passent des articles sur la culture. » (Élu municipal 1)

L'engagement bénévole des néo-ruraux entraîne souvent le développement d'activités originales venant répondre à certains besoins : "Alors, évidemment, tout de suite [cette salle de spectacle] a répondu à un besoin. [...] Alors ça nous permet de voir des spectacles [...] qui nous font à la fois connaître des gens, des locaux là, qu'ils soient néo-ruraux ou non [...] qui ont des choses à offrir, et qui amènent des choses de l'extérieur ici aussi. [Ces 2 aspects: talents locaux et talents extérieurs] répondent [...] parfaitement bien à un besoin. » (Néo-rurale 1)

Ces nouvelles activités viennent combler certaines lacunes dans les activités culturelles existantes. En outre, elles figurent comme des démarches structurantes pour le développement de la région. Elles contribuent à la mise en valeur d'atouts locaux ainsi qu'à la revitalisation culturelle globale du milieu : « On le voit au niveau des arts, au niveau de la culture. Les gens qui s'installent, ils mettent sur pied de nouveaux organismes, ils créent des nouveaux festivals, ils font des choses comme cela. Alors, j'ai l'impression que cela va être de plus en plus intéressant dans le coin. Et aussi sur le plan du patrimoine, il y a une sensibilité de plus en plus grande à l'égard des bâtiments qu'il faut sauvegarder. » (Néo-rurale 19)

Se remarque l'émergence d'entreprises culturelles en économie sociale qui s'inscrivent dans de nouvelles formes de développement soucieuses de démocratisation, de solidarité et d'utilité sociale ${ }^{7}$. Artistes et artisans en réseau coopératif (ARC) en est un exemple, alors que les artistes locaux - tant nouveaux que de longue date - ont créé une coopérative pour la mise en marché de leurs œuvres auprès du milieu corporatif. Celui-ci est encouragé à acquérir des œuvres pour offrir en cadeaux, décorer les lieux de travail et promouvoir les talents locaux.

\section{Facteur d'intégration}

Grâce à leur engagement dans des activités culturelles, les néo-ruraux se construisent un nouveau réseau social qui leur offre, selon leurs besoins, un soutien dans le démarrage d'une nouvelle carrière, une collaboration dans un projet commun, une solidarité lors 
de difficultés. Fréquemment, ce réseau permet de développer des amitiés profondes avec des ruraux de longue date ou d'autres nouveaux résidents: "Ma conjointe avait commencé à faire de la mosaïque. [...] En allant sur la route des vins, il y a beaucoup d'artisans. Elle a travaillé en parallèle avec des artisans, en collaboration. [...] Un atelier l'a aidée à partir son projet.» (Néo-rural 26) «Je suis impliquée dans plusieurs compagnies de théâtre. J'ai rencontré tous mes meilleurs amis là-dedans et puis on est plusieurs qui faisons ensemble soit une pièce de théâtre, ou on fait beaucoup de bénéfices pour l'hôpital et tout ça. Ça fait que je pourrais vous dire que c'est surtout ces personnes-là que je fréquente. [...] Les amis que vous vous faites là-dedans deviennent assez vite des amis intimes. [...] Il y a un bon mix, pas juste du monde d'ici. [...] Cela aide beaucoup d'être dans le domaine artistique. [...] Cela aide beaucoup pour les contacts. » (Rurale de longue date 41)

En fait, le bénévolat vient faciliter l'intégration des nouveaux ruraux en leur permettant un ancrage dans la communauté et le renforcement de leur sentiment d'appartenance au milieu, comme le dit si bien cette bénévole : «Le fait de s'impliquer [...] c'est sûr qu'il $\mathrm{y}$ a une forme de reconnaissance de la part du groupe. Donc, cela fait tout simplement cimenter un peu plus. [...] Tu ne feras jamais partie du village, mais tu ne fais plus partie de la ville. Il y a comme un déplacement entre le nous et les autres. Je commence à faire partie du nous, mais pour faire partie du nous, il faut quelque part s'impliquer. » (Néo-rurale 12)

\section{Nouveau métissage culturel}

Plusieurs de ces activités culturelles donnent l'occasion aux néo-ruraux de rencontrer des ruraux de longue date ou des personnes nées dans le territoire de la MRC. Ainsi, elles permettent des échanges, une collaboration, un élargissement des réseaux et un certain métissage culturel, comme l'observent ces personnes : « La projection du film de Séraphin, cela les a tous réunis dans l'église qui est la salle de projection. Cela a réunit les deux communautés [nouvelle et de longue date]. Il n'y avait plus vraiment de distinction entre les deux. C'est que ces gens-là sont tous venus à la salle regarder, un peu comme la messe de minuit là, où tout le monde se rencontre et jase. [...] Mais cet événement-là a été créé par des néo-ruraux, justement pour essayer de rapprocher les deux communautés. » (Élu municipal 1) «Il y a vingt ans, il y avait beau- coup plus d'arts visuels. Mais depuis disons dix ans, c'est aussi les arts de la scène qui prennent de la place, et beaucoup avec des nouveaux arrivants, je dirais en collaboration [avec des ruraux de longue date]. » (Rurale de longue date 35)

\section{Attraction de nouvelles populations}

Il est indéniable qu'un dynamisme culturel dans la communauté aura comme conséquence d'attirer une nouvelle population désirant fortement un milieu de vie comportant un bon éventail d'activités culturelles. Il attirera également des artistes à la recherche de lieux pour créer, des visiteurs ainsi que des touristes : «C'est une des raisons pour lesquelles le monde vient dans Brome-Missisquoi, c'est vraiment artistique. Il y a beaucoup de peintres, de musiciens, de comédiens et tout. Ils sont attirés par ce qu'on a ici comme vie artistique. Cela fait que, si vous êtes dans cette vie, je trouve que le monde se connaît assez vite [...] cela se mélange très bien » (Rurale de longue date 41) «Je pense qu'il y a beaucoup de gens qui ont un espace privilégié ici pour s'éclater. Et là, je pense aux peintres, aux sculpteurs, aux potiers, aux écrivains. [...] Cela peut devenir une plaque tournante pour des gens de l'extérieur pour venir voir cela. Il y a un gros potentiel [...] pour l'inspiration, pour le tourisme, pour promouvoir le Tour des Arts, la Route des vins, tous les vignobles qu'on a, et les festivals Brome Fair, etc. [...] On peut accueillir des gens avec tout cela, c'est super! C'est une richesse qu'on a ici. » (Néo-rural 10) «C'est en ayant visité le coin qu'on a vraiment trippé sur la place. [...] On s'est rendu compte qu'il y avait beaucoup de monde de nos âges, avec des enfants. Puis, ce qu'on aime aussi du coin, c'est qu'il y a beaucoup d'artistes, d'artisans. [...] C'est cela qui a fait qu'on est venu. Tu sais, on voulait aller en campagne, mais on ne voulait pas aller de l'autre bord de Québec, on ne voulait pas aller dans les Laurentides. » (Néo-rural 26)

\section{Conclusion}

Cette première analyse permet déjà d'entrevoir que les retombées culturelles liées à la présence des néoruraux vont bien au-delà des considérations économiques. L'apport de ces nouveaux ruraux dans les arts et la culture est multiple et diversifié, comme on a pu le constater. Ils contribuent ainsi à la revitalisation rurale de leur milieu, la culture servant alors de levier essentiel du développement global et d'espace d'expression 
d'une identité propre. Signe de la mutation contemporaine en milieu rural, la migration de populations urbaines vers les campagnes est donc un phénomène singulier qui ne manque pas d'avoir de nombreuses répercussions sur la production culturelle locale et ses diverses manifestations artistiques et culturelles.

Les ruraux - nouveaux et de longue date - sont nettement des créateurs et des diffuseurs de culture novatrice.

La participation culturelle en milieu rural figure comme un nouvel espace de collaboration, de solidarité et de mixité de populations variées - autant nouvelle que de longue date - qui se construit autour de la culture et du bénévolat. La culture a, en effet, la capacité d'être rassembleuse, et elle participe à l'édification d'une nouvelle ruralité où des liens sociaux inédits sont porteurs d'une cohésion sociale renouvelée. En favorisant un contact et des échanges entre diverses populations rurales, la culture leur permet de mieux se connaître et d'atténuer ainsi les clichés et les fausses représentations des uns sur les autres. Elle permet également d'adoucir les antagonismes et les clivages socio-économiques susceptibles de se manifester entre les divers sous-groupes de ruraux, notamment autour de projets de développement intensif, de l'embourgeoisement des campagnes et, par conséquent, de l'accès inégal au logement et à la propriété.

Les ruraux - nouveaux et de longue date - sont nettement des créateurs et des diffuseurs de culture novatrice, et non simplement des consommateurs, tels que je 1'ai déjà affirmé ailleurs ${ }^{8}$. Reste à voir de façon plus approfondie « la nouvelle culture rurale » qui en ressortira et ses traits distinctifs par rapport à la culture urbaine. Comment s'exprimera concrètement ce nouveau métissage culturel entre les diverses populations rurales ? Se traduira t-il différemment selon les diverses régions québécoises? Quelles formes prendra cette nouvelle culture rurale dans l'avenir ?

\section{Notes et références}

1 Guimond L. et M. Simard (2007). «Néo-ruralité au Québec: survol de la diversité des nouveaux ruraux dans Brome-Missisquoi », Journal of Eastern Townships Studies / Revue d'études des Cantons de l'Est, $\mathrm{n}^{\mathrm{o}}$ 29-30, Université Bishop, p. 99-119.

2 Simard, M. (2007). « Nouvelles populations rurales et conflits au Québec: regards croisés avec la France et le Royaume-Uni », Géographie, Économie, Société, numéro spécial sur "Conflits d'usages et dynamiques spatiales » (dir. T. Kirat et A.Torre), vol. 9, $\mathrm{n}^{\circ}$ 2, avril-juin, Lavoisier, France, p. 187-213.

3 Pour le lecteur intéressé, les résultats des sondages des deux MRC peuvent être téléchargés sur le site Web de l'INRS sous Travaux et publications : www.ucs.inrs.ca, et sous le titre Nouvelles populations dans le Québec rural (2008).

4 Reimer, B. (2007). «The Eastern Townships in the New Rural Economy: Lessons from Pan-canadian Research », Journal of Eastern Townships Studies, $\mathrm{n}^{\circ}$ 29-30, Université Bishop, p. 27-44. L'auteur y souligne les atouts humains, sociaux, culturels, naturels et géographiques de cette région où se situe la MRC de Brome-Missisquoi.

5 Hill Strategies (2003). Les bénévoles dans les organismes artistiques et culturels au Canada.

6 Hill Strategies (2006). Petites municipalités urbaines et rurales artistiques du Québec. Article disponible à l'adresse suivante:

www.hillstrategies.com/docs/Artistes_petites_QC.pdf.

Bricault C. et M. Simard (2008). Atouts, difficultés et défis des entreprises culturelles d'économie sociale en milieu rural : revue de littérature et premiers résultats de recherche dans Brome-Missisquoi, Cahiers de l'ARUC-Économie sociale, Montréal. Voir la brochure de vulgarisation sur le site du CLD de Brome-Missiquoi : Culture et Cie en milieu rural et à Brome-Missisquoi. http://www.bromemissisquoi.ca/fr/

8 Simard, M. (2002). «Espace rural et culture», dans D. Lemieux (dir.), Traité de la culture, Les Presses de l'Université Laval et les Éditions de l’IQRC, p. 163-180. 